RUNNING HEAD: Evaluation of the NHS Health Trainer Service

Behaviour change among overweight and socially disadvantaged adults: a longitudinal study of the NHS Health Trainer Service

\author{
Benjamin Gardner* \\ Health Behaviour Research Centre \\ University College London, Gower Street, London, WC1E 6BT \\ James Cane \\ Centre for Outcomes Research and Effectiveness \\ University College London, Gower Street, London, WC1E 6BT \\ Nichola Rumsey \\ Department of Psychology \\ University of the West of England, Coldharbour Lane, Bristol, BS16 1QY \\ Susan Michie \\ Centre for Outcomes Research and Effectiveness \\ University College London, Gower Street, London, WC1E 6BT \\ Email: b.gardnersood@ucl.ac.uk.
}

* Corresponding author.

Tel: 02076798267.

\title{
Acknowledgements
}

Our thanks to Fiona Adshead, who devised the Health Trainer scheme as part of Choosing Health whilst Deputy Chief Medical Officer and offered helpful comments on a draft of the manuscript, and to Raj Bhopal, Aziz Sheikh, and Falko Sniehotta for helpful comments on an earlier draft of the manuscript. We also thank Janet Andelin, Rachel Carse, Ertan Fidan, David Hopkinson, Maureen Murfin, and Jan Smith for their input to the project. 


\title{
Behaviour change among overweight and socially disadvantaged adults: a longitudinal study of the NHS Health Trainer Service
}

\begin{abstract}
Social disadvantage is associated with being overweight, a poor diet, and physical inactivity. The NHS Health Trainer Service is a national initiative designed to promote behaviour change among socially disadvantaged people in England and Wales. This study reports pre-post changes in BMI, associated behaviours and cognitions among service users who set dietary or physical activity goals during a 12month period $(2008-09 ; N=4,418)$. Sixty-nine percent of clients were from the two most deprived population quintiles and $94.7 \%$ were overweight or obese. Mean BMI decreased from 34.03 to 32.26 , with overweight/obesity prevalence decreasing by $3.7 \%$. There were increases in fruit and vegetable consumption, reductions in fried snack consumption, increases in frequency of moderate or intensive activity, and gains in self-efficacy and perceived health and wellbeing. Clients with higher BMI, poorer diet or less activity at baseline achieved greater change. Findings suggest that the NHS Health Trainer Service has the potential to improve population health and reduce health inequalities through behaviour change.
\end{abstract}

Keywords: Health behaviour, health inequalities, social disadvantage, overweight, ethnicity, policy 


\section{Behaviour change among overweight and socially disadvantaged adults: a longitudinal study of the NHS Health Trainer Service}

\section{INTRODUCTION}

Overweight and obesity are associated with increased mortality and morbidity (Kopelman, 2007), placing a significant burden on healthcare resources, with direct annual costs to the UK National Health Service (NHS) estimated at $£ 4.2$ bn (Butland et al, 2007). Survey data estimates that, in England, $61 \%$ of adults are overweight (Body Mass Index $[\mathrm{BMI}] \geq 25)$ or obese (BMI $\geq 30$ ) (Tabassum, 2010).

In the UK, overweight and obesity is associated with lower socioeconomic status (SES; National Obesity Observatory, 2010) and, among women, with Black African and Black Caribbean groups (Hirani \& Stamatakis, 2006). Ethnic differences in England are likely to reflect SES inequalities, because Black and Minority Ethnic people are more likely to live in economically deprived communities (Tinsley \& Jacobs, 2006). These disparities are also reflected in health-related behaviours. Whereas $32 \%$ of men and $37 \%$ of women in the highest income quintile of the UK population consume the Government-recommended five or more fruits and vegetables $(\mathrm{F} \& \mathrm{~V})$ per day, only $18 \%$ and $19 \%$ respectively of those in the lowest quintile do so (Ogunbadejo \& Nicholson, 2010). Of those in the highest income quintile, $42 \%$ of men and $34 \%$ of women undertake at least five 30-minute sessions of moderate or intensive physical activity (PA) per week, compared to $31 \%$ and $26 \%$ respectively in the lowest quintile (Roth, 2009).

Inequalities are also found in the success rates of interventions to increase healthy eating (HE) and PA. People from disadvantaged communities (i.e. economically deprived and minority ethnic groups) are typically harder to recruit to, 
and retain in, such interventions (Chinn, White, Howel, Harland \& Drinkwater, 2006). This does not necessarily imply less motivation among disadvantaged groups; evidence from the smoking literature suggests that lower SES smokers want, and try, to quit as much as other smokers, but are less likely to succeed (Kotz \& West, 2009). Disadvantaged groups have reduced access to the material and social resources needed to sustain behaviour change over time. There is a paucity of HE or PA interventions specifically targeted at low-SES groups: recent reviews identified only seven interventions aimed at low-income adults (published between 1996 and 2006; Michie, Jochelson, Markham \& Bridle, 2009), but 122 among the general population (Michie, Abraham, Whittington, McAteer \& Gupta, 2009).

Between 2003 and 2010, a team of health psychologists collaborated with UK Department of Health (DH) policymakers to devise strategy to reduce health inequalities rooted in behaviour change. This arrangement led to the development of the NHS Health Trainer Service (HTS), a nationwide public health initiative based on individualised support for behaviour change among members of disadvantaged communities. Health Trainers (HTs) are lay community members who typically come from the same backgrounds as the target group and are trained to use evidence-based behaviour change techniques (Michie, Rumsey et al, 2008). The role of HTs is to assess health and lifestyle risks, reinforce motivation, build confidence and skills, and collaborate with clients to set goals (e.g. weight loss of $5 \mathrm{~kg}$ ) and make specific, achievable and realistic action plans (e.g. eating two less fried snacks per day on at least 4 days next week). While most HTs (58\%) operate in a paid role, a considerable proportion of HTs (42\%) are volunteers (DH, 2010). The aim of recruiting HTs from local communities is to increase understanding of clients' circumstances to help them choose more realistic goals and specific plans to attain them (DH, 2004). HTs that 
reflect characteristics of clients from local communities (e.g. those matched in ethnicity to clients) are more likely to be effective role models, an important facilitator of behaviour change (Bandura, 1977). Clients can refer themselves or may be referred by others working in health or social care. Most are seen individually and the number of sessions varies according to client need or engagement.

The HTS is, to our knowledge, the only national public health service based on health psychology theory and evidence. The service is thus based on evidence that sustained behaviour change requires not only motivation, but also self-regulatory skills (goal-setting, action and coping planning, awareness of environmental triggers to unwanted actions) and self-efficacy for initiating and maintaining change (DH, 2004). These principles are central to evidence-based theories, such as Control Theory (Carver \& Scheier, 1982; Michie, Abraham et al, 2009), the Health Action Process Approach (Schwarzer, 1992, 2008), and Social Cognitive Theory (Bandura, 1997). HTs receive a handbook which lists behaviour change techniques known to bolster motivation, skills and confidence (e.g. action planning, barrier identification, general encouragement, using contingent rewards; Abraham \& Michie, 2008; Michie, Ashford et al, 2011; Michie, Rumsey et al, 2008).

The HTS is notable for the extent of input from health psychologists in its design, implementation and evaluation. A team of health psychologists wrote the HT training handbook, and advised the DH on the development of a set of competencies that form the basis of a recognised vocational qualification for HTs. The team negotiated the creation of a database to detect changes in behaviour and cognition using validated measures, procured DH support for use of the database across all HTSs, and successfully argued for the ringfencing of intervention content, change techniques and outcome measures to prevent the service shifting from its evidence 
base. Additionally, the team provided long-term support to the HTS, the DH, and regional HT managers and practitioners, and led and evaluated an initial Londonbased pilot of the service (see Wilkinson, Sniehotta \& Michie, 2011).

Since its launch in 2007, the HTS has grown rapidly, with an estimated 1900 HTs in employment in 2010 (Gowers, 2010; D Smith, Gardner \& Michie, 2008; Wilkinson, Jain \& Hyland, 2007). Baseline data indicated that a pilot HTS based in inner London successfully reached disadvantaged and typically hard-to-reach clients who engage in unhealthy behaviours and typically have no plans to change their behaviour prior to using the service (Wilkinson et al, 2011). Local evaluation data from other HTSs have shown the service to be valued by stakeholders, HTs and clients (Ball \& Nasr, 2011; South, Woodward \& Lowcock, 2007).

This study uses a national dataset to address the following questions:

(1) Is the HTS used by members of disadvantaged communities (those in deprived areas and minority ethnic groups)?

(2) Do BMI, associated behaviours (dietary consumption, physical activity), and predictive cognitions change among clients who set HE and PA goals?

(3) Does change vary according to deprivation and ethnicity, and whether HTs are from similar ethnic backgrounds to clients?

\section{METHOD}

\section{Procedure and design}

Data were recorded in a national database by HTs. This is one of several sources of national HT data, but is the only database requiring systematic reporting of behaviour data. In 2008-09, when the present data were collected, HTSs were encouraged but not compelled to use this database. Cross-referencing with other sources suggests that 
the 75 local health service organisations (Primary Care Trusts) that provided data for the current analyses represent $62 \%$ of the service as at 2009 (J Smith, Gardner \& Michie, 2009).

Data were collected at sequential timepoints: (i) at first contact, when client demographics (age, gender, ethnicity, deprivation), behaviour (HE and/or PA), height and weight, self-efficacy, and perceived health and wellbeing were recorded; (ii) when clients set their goals and plans; and (iii) at a final assessment when all baseline measurements (except demographics) were repeated (Figure 1). Many aspects of the HT-client consultation process are however personally tailored to clients' needs and circumstances, including the timing of goal-setting and follow-up, the duration of each consultation, and the number of follow-up reviews. 'Post-HTS' data reported herein relate to the final post-baseline assessment for which data were recorded for each client.

Due to expected poor literacy levels among many clients, HTs were encouraged to read questions aloud to clients and recorded their verbal responses. An uncontrolled before-after design was used.

\section{INSERT FIGURE 1 HERE}

\section{Sample}

Of 27,670 first-time users of the HTS between $1^{\text {st }}$ April 2008 and $31^{\text {st }}$ March 2009, 140 were ineligible for the service (reasons for ineligibility were not recorded), 2,544 were under 18 or did not provide age data, 9,265 did not set goals and there were missing progress data for 8,829 clients. From Service Manager meeting reports, many HTs appeared not to perceive data collection to be an important part of the service and so did not comply with the central request to do so. 4,418 clients ( $16 \%$ of all first-time 
users, $18 \%$ of eligible first-time adult users) set primary goals ${ }^{1}$ relating to HE or PA (rather than, e.g., smoking) and had data on goal achievement and behaviour change available, so were entered into analyses.

The sample represents $96.0 \%$ of all clients who set goals and for whom goal achievement and pre-post behaviour data were available. The remaining $4 \%$ of clients set goals relating to decreasing or ceasing alcohol consumption or smoking, or unspecified 'other' changes.

\section{Measures}

Ethnic group was based on UK census classifications, and HT-client ethnicity similarity, i.e. whether HT and client were of the same ethnic group, was recorded. Age was calculated from self-reported date of birth and date of baseline assessment. Deprivation was assessed by mapping client postcode to national 'Super Output Areas' (SOAs; geographical units with an average population of 1,500). Deprivation status for each SOA is determined by the Index of Multiple Deprivation, which summarises seven deprivation indicators (income; employment; health and disability; education, skills and training; housing and services; crime; and living environment; Department for Communities and Local Government, 2011). Each SOA is sorted into quintiles to denote deprivation status within the population.

$B M I$ was calculated from self-reported or objectively measured height and weight. Records of whether data were self-reported or objective were not kept by

\footnotetext{
${ }^{1}$ HTs are instructed to encourage clients to pursue only one behaviour change goal at a time, as this is expected to increase the likelihood of success (Michie, Rumsey et al, 2008). Nonetheless, clients are able to set multiple goals, and some may have targeted both HE and PA change. Records of whether clients set multiple goals, and which behaviours were targeted in these instances, were not kept. HTs recorded only the primary behaviour change goal for each client, and we have used this information to categorise clients as pursuing either HE or PA goals. Hence, while it is unclear how many clients in our sample targeted both HE and PA, clients who set HE goals are distinct from those who set PA goals in our analyses.
} 
HTs. BMI data were used to categorise participants as underweight $(\mathrm{BMI}<18.5)$, normal weight $(\mathrm{BMI} \geq 18.5<25)$, overweight $(\mathrm{BMI} \geq 25<30)$, or obese $(\mathrm{BMI} \geq 30)$.

Health behaviours. Clients with PA goals reported the number of 30-minute moderate and/or 20-minute intensive PA sessions undertaken over the previous week. Moderate activity was defined as activities that "make you breathe a bit harder than normal", e.g. "carrying light loads, cycling or walking at a reasonable pace". Intensive activity was defined as activities that "make you breathe much harder than normal", e.g. "heavy lifting, digging, aerobics or fast cycling". Clients with HE goals reported the number of $F \& V$ portions and/or quantity of fried snack foods consumed daily over the past week.

General self-efficacy was assessed using eight items (e.g. "When facing difficult tasks, I am certain that I will accomplish them", strongly disagree [0] strongly agree [4]; Chen, Gully \& Eden, 2001). Higher scores on the summed scale (range 0-32) indicate higher self-efficacy $(\alpha=.89)$.

Perceived general health was measured using a visual analogue scale, with clients indicating their current health status from 0 ('poor') to 100 ('perfect'; Lorig, Stewart, Ritter, Gonzalez, Laurent \& Lynch, 1996).

Wellbeing was assessed using the five-item WHO Wellbeing Index (World Health Organisation, 1998), which records the frequency of positive experiences over the previous two weeks (e.g. "Over the last two weeks I have felt calm and relaxed"; At no time [0] - All of the time [5]). Higher scores on the summed scale (0-25) indicate better wellbeing ( $\alpha=.76)$.

Since only HT and client demographics were mandatorily recorded, there was variation between HTSs in whether data was recorded (e.g. height and weight, behaviours). 


\section{Data analysis}

Data cleaning. Prior to analysis, outlier BMI or behaviour scores (values with a relative $\mathrm{z}$-score outside of \pm 3.0 ), and cases where HTS attendance was less than one week ( $<7$ days) in duration were removed from analysis as they were judged to be either data reporting pilot runs or data entry errors. This excluded less than $2.1 \%$ of cases.

Biased loss to follow-up. Potential differences were explored between (a) clients who set any goals versus clients who did not set goals, and (b) of clients who set HE or PA goals, those for whom baseline and follow-up data were available versus those for whom such data were unavailable. Chi-square analyses investigated whether there were differences in ethnicity and deprivation between these groups, and t-tests assessed BMI differences.

BMI, behaviour and cognition changes were assessed using paired sample ttests for pre-post differences. Effect size $d$ was calculated based on raw means and standard deviations (SDs; Dunlop, Cortina, Vaslow \& Burke, 1996) and $d \geq .20, .50$ and .80 were interpreted as small, medium and large effects respectively (Cohen, 1992).

The consistency of change across demographic groups was investigated by entering client ethnicity, deprivation, and HT-client ethnicity similarity into three ANCOVAs, controlling for baseline scores on the outcome variable, duration of service use and number of progress reviews ${ }^{2}$. To achieve sufficient analytic power, the small number of clients of 'mixed' and 'other' ethnicity (see Table 1) were removed from analyses, and Asian and Black ethnicities were represented by two

\footnotetext{
${ }^{2}$ Multivariate analyses of covariance (MANCOVAs) were not run because missing data substantially reduced usable Ns.
} 
dummy variables ('Asian vs White and Black', 'Black vs White and Asian')³. Comparison of coefficients for the two variables permits estimation of effects observed between all three ethnicity clusters. To investigate whether the most socially disadvantaged clients derived equal benefit to others, the most deprived $20 \%$ of the population was compared with the remaining $80 \%$. Significant effects within the ANCOVA model were explored via comparison of estimated marginal subgroup means (EMM).

Predicting BMI and behaviour change. The unique contribution of demographic variables to predicting BMI and behaviour change was assessed using multiple linear regressions to control for other relevant variables. A four-step model was employed, with baseline behaviour values entered at the first step, duration of service use and number of reviews at the second, a duration $\mathrm{x}$ number of reviews interaction term at the third, and demographic variables at the fourth. Significant interaction terms were examined using simple slope analyses (Aiken \& West, 1991), to model effects of service use duration at the mean, one SD below, and one SD above the mean number of reviews. We report only regression models which significantly improved the explanation of variance offered by the model at a previous step, but were not further improved at subsequent steps.

\section{RESULTS}

Unless otherwise stated, all effects were statistically significant at $p<.001$. The available sample size $(\mathrm{N})$ varies due to missing data.

Who uses the HTS?

\footnotetext{
${ }^{3}$ We recognise the inherent limitations of collapsing disparate ethnic groups together (Bhopal, 2004) and have kept ethnic groups separate where possible.
} 
Of 4418 clients, 3503 (79\%) were female and 660 (17\%) were of Asian or Black ethnicities (Table 1). Nearly half (1836 clients; 43.2\%) were from the most deprived quintile of the UK population, and a further quarter (1093 clients; $25.7 \%$ ) were from the second most deprived quintile. Of 3759 clients for whom BMI data were available, 2717 clients (72.3\%) were obese and $824(22.4 \%)$ were overweight at baseline $^{4} .3346$ clients $(75.7 \%)$ set HE goals and 1072 (24.3\%) set PA goals. Overweight and obesity prevalence was higher at baseline among clients setting HE goals $(95.4 \%)$ than clients setting PA goals $\left(88.8 \% ; \chi^{2}[3]=85.39\right)$, but there were negligible other demographic differences between these two groups.

The mean duration of HTS attendance was 6.14 months $(S D=4.10 ; N=$ 4347), and clients typically had between one and two progress reviews ( $M=1.51, S D$ $=2.07 ; N=3298)$. Clients with PA goals attended the service for longer $(M=6.77$ months; $S D=4.49 ; d=.16)$ and had more reviews $(M=2.03, S D=2.28 ; d=.29)$ than clients with HE goals $(M=5.98, S D=3.97$ and $M=1.34, S D=1.97$ respectively).

\section{INSERT TABLE 1 HERE}

Is the sample affected by selection bias?

A greater proportion of White (35\%) and Asian (30\%) clients set goals than did Black clients $(25 \%)\left(\chi^{2}[2]=97.15\right)$. More goals were set in the least deprived quintile than in the rest $\left(42 \%\right.$ vs $\left.35-38 \% ; \chi^{2}[4]=26.62\right)$. Of clients who set HE or PA goals, a greater proportion of White clients (35\%) had pre-post data than did Asian (30\%) or Black clients $(27 \%)\left(\chi^{2}[2]=27.17\right)$. Pre-post data were available for $45 \%$ of clients in the least deprived quintile, but for only $29 \%$ in the most deprived group $\left(\chi^{2}[4]=\right.$

\footnotetext{
${ }^{4}$ Overweight and obesity prevalence $(94.7 \%)$ was higher at baseline among clients setting HE or PA goals than those with goals unrelated to HE or PA $\left(63.4 \% ; \chi^{2}[3]=265.04\right)$.
} 
149.21). Clients with pre-post data had a higher BMI (33.36) than clients without these data $(28.69)(\mathrm{t}[945.11]=18.99)$.

\section{Do behaviours and cognitions change following use of the HTS?}

Among all clients, BMI reduced by 1.77 points, from 34.03 to $32.26(N=3759 ; d=$ .28) (Table 2). Overweight/obesity prevalence decreased from $94.7 \%$ to $91.0 \%$. The proportion of obese clients decreased from $72.3 \%$ to $60.1 \%$. Self-efficacy, perceived general health and wellbeing all increased markedly $(d=.47, .94$, and .92 respectively).

Among clients with HE goals, BMI reduced by 1.88 points, from 34.33 to 32.45 (5.5\% decrease; $N=3164 ; d=.30)$, overweight/obesity prevalence decreased from $95.6 \%$ to $92.3 \%$, and obesity from $74.3 \%$ to $61.0 \%$. Clients with HE goals reported a $41 \%$ increase in $\mathrm{F} \& \mathrm{~V}$ intake, from 3.08 to 5.23 daily portions $(d=.97)$. The proportion of clients consuming five or more portions of $\mathrm{F} \& \mathrm{~V}$ increased from $24.8 \%$ to $60.5 \%$. Mean fried snack consumption decreased by $60 \%$, from 1.99 to 0.79 servings per day $(d=.85)$. There were considerable increases in self-efficacy $(d=$ .46), perceived general health $(d=.95)$ and wellbeing $(d=.85)$.

Among clients with PA goals, BMI reduced by 1.24 points, from 32.46 to 31.24 (3.8\% decrease; $N=595 ; d=.18$ ), overweight/obesity prevalence decreased from $89.7 \%$ to $84.2 \%$, and obesity from $61.7 \%$ to $55.6 \%$. Clients with PA goals reported a $63 \%$ increase in number of intensive PA sessions per week, from 0.63 to $1.71(d=.46)$, and the proportion of clients engaging in 5 or more intensive sessions weekly increased from $3.9 \%$ to $11.6 \%$. The number of moderate PA sessions per week increased by $36 \%$ from 3.06 to $4.77(d=.42)$ and the proportion undertaking 5 or more moderate sessions weekly increased from $24.4 \%$ to $45.5 \%$. There were 
considerable increases in self-efficacy $(d=.53)$, perceived general health $(d=.88)$ and wellbeing $(d=1.06)$.

\section{INSERT TABLE 2 HERE}

\section{Do all clients experience behaviour changes equally?}

Ethnicity. There were no differences in BMI change between ethnic groups for the whole sample. Among clients with HE goals, Asian clients achieved less BMI change than did White clients $\left(0.55 \mathrm{BMI}\right.$ points; $F[1,3050]=21.62, \mathrm{Eta}^{2}=.007 ; p=$ .006). BMI change among Black clients did not differ from Asian or White clients. Ethnicity was not associated with F\&V, nor with fried snack consumption. Among clients with PA goals, ethnicity was not associated with BMI, nor behaviour.

Deprivation. Clients from the least deprived $80 \%$ of the population achieved more BMI change than did the most deprived clients $(0.28$ BMI points; $F[1,3572]=$ 12.13, $\left.\mathrm{Eta}^{2}=.003 ; p=.001\right)$. Among clients with HE goals, less deprived clients achieved more BMI reduction $\left(0.24 \mathrm{BMI}\right.$ points; $F[1,3010]=7.77, \mathrm{Eta}^{2}=.003$, $p=.005)$. Deprivation was not associated with $\mathrm{F} \& \mathrm{~V}$ nor fried snack consumption changes. Among clients with PA goals, deprivation was not associated with BMI, nor behaviour change.

HT-client ethnicity similarity. Clients of similar ethnicity to HTs achieved greater BMI reduction than did those who were not $(0.28 \mathrm{BMI}$ points; $F[1,3708]=$ $\left.10.14, \mathrm{Eta}^{2}=.003 ; p=.001\right)$. Among clients with HE goals, those of similar ethnicity to HTs achieved higher BMI reductions $\left(0.31 \mathrm{BMI}\right.$ points; $F[1,3123]=10.75 ; \mathrm{Eta}^{2}$ $=.003 ; p=.001)$, increases in $\mathrm{F} \& \mathrm{~V}\left(0.33\right.$ more portions; $F[1,2328]=13.80 ; \mathrm{Eta}^{2}$ $=.004)$, and decreases in fried snack consumption (0.13 fewer snacks; $F[1,1834]=$ 11.52; $\left.\mathrm{Eta}^{2}=.001 ; p=.001\right)$. Among clients with PA goals, ethnicity similarity was not associated with BMI nor intensive PA, but those of similar ethnicity to HTs showed 
greater increases in moderate PA $\left(0.70\right.$ more sessions; $F[1,894]=10.05 ; \mathrm{Eta}^{2}=.007$; $p=.002)$.

\section{Predicting behaviour change}

Baseline BMI $(\beta=.30)$, duration of contact $(\beta=.08)$, client ethnicity (Asian; $\beta=$ $.06)$, and an interaction between duration and number of reviews $(\beta=-.05)$ predicted $11 \%$ of variance in BMI change (Table 3). Longer duration of service use had greater positive impact on BMI change among clients who had fewer reviews $(\beta=.12)$ relative to those who had more reviews $(\beta=.08)$. Clients with higher baseline BMI and of non-Asian ethnicities experienced greater BMI change.

Among clients with HE goals, baseline BMI $(\beta=.27)$, duration $(\beta=.11)$, client ethnicity (Asian; $\beta=-.07)$, and a duration $\mathrm{x}$ reviews interaction $(\beta=-.06)$ predicted $10 \%$ of variance in BMI change. Clients with higher baseline BMI and nonAsian clients were more likely to experience change. Longer service use was more strongly positively associated with BMI change among clients who had fewer reviews $(\beta=.14)$ than those who attended more reviews $(\beta=.10)$. Baseline scores predicted $82 \%$ of variance in fried snack consumption change and $21 \%$ variance in $\mathrm{F} \& \mathrm{~V}$ change. Greater change was observed among clients snacking more $(\beta=.91)$, and those eating less $\mathrm{F} \& \mathrm{~V}(\beta=-.46)$ at baseline.

Among clients with PA goals, baseline scores predicted $15 \%$ of the variance of BMI, and $21 \%$ and $40 \%$ of the variance of intensive and moderate activity, respectively. There was greater change among clients with higher baseline BMIs and fewer baseline intensive and moderate activity sessions $(\beta \mathrm{s}=.38,-.64$ and -.45 , respectively). 
In sum, health behaviour change was consistently predicted by baseline scores, such that those clients with most room for improvement achieved greater change. BMI reduction among clients with HE goals was also associated with ethnicity, with Asian clients experiencing less change. Clients who attended fewer progress reviews benefitted more from longer service use duration.

\section{DISCUSSION}

This study suggests that the HTS is achieving its aim of promoting health via behaviour change among disadvantaged groups. The HTS successfully targeted disadvantaged clients: nearly half were from the most economically disadvantaged $20 \%$ of the population, and almost all clients were overweight or obese. Clients experienced changes in targeted behaviour (dietary consumption or physical activity), BMI, self-efficacy, perceived health and wellbeing. Caution is however needed in interpreting these results, in light of inconsistencies between HTs and services in intervention delivery and data collection methods, and the absence of a control group.

Greater change was observed among clients with higher BMI, poorer diet or lower levels of physical activity prior to using the service. Clients from the most deprived quintile and of Asian ethnicities were less likely to set behaviour change goals and achieved less BMI change than others. It is unclear whether this reflects lower motivation to change, restricted opportunities for healthy eating or physical activity, lower self-efficacy, and/or poorer quality HTSs serving these clients. Nonetheless, the HTS appears to be reaching and engaging these hard-to-reach clients in behaviour change attempts, which many health interventions have failed to do (e.g. Bernal \& Sharron-del-Rio, 2001). More evidence is needed regarding the strategies most likely to translate this engagement into BMI change for those from the most 
deprived communities, or those of Asian ethnicity. A framework is available which specifies discrete psychological domains that underpin and explain the behaviour change process (e.g. knowledge, skills, environmental context and resources; Michie, Johnston, Abraham, Lawton, Parker, \& Walker, 2005). Applying this framework within qualitative interview or quantitative survey designs may help to pinpoint reasons for lack of change among some client groups.

There were significant gains in the number of clients meeting UK Government HE and PA recommendations. Such behaviour changes among disadvantaged groups have the potential to reduce social inequalities in health, overweight and obesity (Michie, Jochelson et al, 2009). BMI reduction of over 5\%, achieved amongst clients with HE goals, is considered to significantly lower the risk of cardiovascular disease amongst obese people (Blackburn, 1995). Baseline scores reliably predicted greater change in BMI and behaviour, indicating that clients with poorer diet or who were less physically active, and so most likely to benefit from the service, typically achieved greatest change. This could however reflect methodological artifice, such as regression to the mean, whereby atypical baseline values naturally move closer to true scores at follow-up, rather than specific intervention effects.

Clients also reported enhanced self-efficacy following use of the HTS. This can boost motivation, so increasing the likelihood of clients pursuing further health targets after disengaging from the HTS (Bandura, 1997), thereby sustaining HTS impact over time. Longitudinal research, with objective behaviour measures and procedures in place to ensure high levels of data collection and retention, is needed to establish whether changes in self-efficacy precede behaviour change, whether behaviour change leads to increased self-efficacy, or whether there is a more complex relationship between HTS use, self-efficacy and behaviour change. 
Although HTs received training in evidence-based behaviour change techniques, including a bespoke handbook (Michie, Rumsey et al, 2008), no data were available to assess the extent to which these techniques were used in practice (i.e. intervention fidelity), and whether this was associated with outcome. Tape-recording a sample of HT-client consultations would permit coding of the behaviour change techniques used in practice (Hardeman, Michie, Fanshawe, Prevost, McLoughlin \& Kinmonth, 2008). This would facilitate not only investigation of fidelity, but also of process-outcome associations, and whether responses to change attempts differ across client groups. Collecting a sufficiently large sample of HT-client consultations would be time-consuming (Hardeman et al, 2008), but such work is necessary to identify mechanisms underpinning observed change and to build evidence to inform future interventions.

Since data were obtained mostly via client self-report and there was no control group, the magnitude of observed changes and causality must be interpreted with caution. Self-report may overestimate behaviour change due to influences such as social desirability and cognitive dissonance (Chaudhury \& Esliger, 2009; Festinger, 1957; Paulhus, 1986). Self-reports should be complemented by objective measures, such as biochemical verification of $\mathrm{HE}$ and PA and measuring weight in the clinic. Our data used a pre-post design; a more rigorous research design could establish whether observed associations can be reliably attributed to the HTS. We echo calls for systematic investment in large-scale prospective assessments of population-level interventions (Boerma \& de Zoysa, 2011). Stepped wedge designs should be routinely considered in guiding the rollout of national intervention programmes, because they involve staggered implementation across constituent regions in a random order and so permit comparison between intervention and 'waiting-list' regions (Craig, Dieppe, 
Macintyre, Michie, Nazareth \& Petticrew, 2008). Behaviour change will only impact on public health when change is maintained in the long-term. Extended follow-up data are needed to assess the stability of observed changes.

We sought to capture a national picture of behaviour change among HTS users over a 12-month period. Yet, comparison with other national data sources suggests that our data captured the activity of only $62 \%$ of HTSs in this period, and just $16 \%$ of first-time clients recorded as accessing the service within these HTSs were eligible for analysis. The database that we drew upon is the only available source of cognition and behaviour data, and so we could not assess the generalizability of the behaviour or beliefs of clients recorded on the database to HTSs more widely. The quantity of missing data attests to the challenges faced in implementing and evaluating a national behaviour change service within the NHS. We have no reason to suspect that clients or HTs were unwilling to provide data. Rather, missing data problems may stem from organisational variations in the history of each service, levels of support from local Primary Care Trusts, and the commitment of local HTS managers to collecting and recording behaviour change and related data within a centralised and standardised database. Although use of the standardised central database was optional in 2008-09, HTSs are now required by the DH to log relevant data in this database, and so missing data problems are likely to be reduced for any future analyses. Even where data were collected, there were differences between HTs and services in the methods used to assess key outcome variables (behaviour and BMI); discussions between the BPS consultancy team and regional HT managers suggested that, even within services, there was variation in whether height and weight were measured objectively, or via self-report. Systematic records of measurement methods were not kept, and so we cannot assess the impact of assessment modes on our findings. Additionally, no data 
were available regarding whether clients pursued both HE and PA goals, and the potential inclusion of clients who modified both energy intake and expenditure may have resulted in greater observed reductions in BMI than can be attributed to either HE or PA change in isolation. Reducing problems of missing or inconsistent data is likely to depend on both raising awareness among service managers and HTs of the importance of robust behavioural data for intervention evaluation purposes, and incentivising data collection.

Notwithstanding these limitations, this study provides the first investigation of health behaviour changes following a nationwide behavioural intervention designed for socially disadvantaged groups based closely on health psychology theory and evidence. The results suggest that the HTS has the potential to improve health among disadvantaged groups, an approach which may help to reduce health inequalities. Replication of these findings is needed, using more objective measures and a more rigorous study design.

\section{References}

Abraham, C., \& Michie, S. (2008). A taxonomy of behavior change techniques used in interventions. Health Psychology, 27, 379-387.

Aiken, L.S., \& West, S.G. (1991) Multiple regression: Testing and interpreting interactions. Thousand Oaks: Sage.

Ball, L., \& Nasr, N. (2011) A qualitative exploration of a health trainer programme in two UK primary care trusts. Perspectives in Public Health, 131, 24-31.

Bandura, A. (1997) Self-efficacy: the exercise of control. New York: W.H. Freeman. 
Bernal, G., \& Sharron-del-Rio, M.R. (2001) Are empirically supported treatments valid for ethnic minorities? Toward an alternative approach for treatment research. Cultural Diversity and Ethnic Minority Psychology, 7, 328-342.

Bhopal, R. (2004) Glossary of terms relating to ethnicity and race: for reflection and debate. Journal of Epidemiology and Community Health, 58, 441-445.

Blackburn, G. (1995) Effect of degree of weight loss on health benefits. Obesity Research, 3 (Suppl 2), S211-S216.

Boerma, T., \& de Zoysa, I. (2011) Beyond accountability: learning from largescale evaluations. The Lancet, 378, 1610-1612.

Butland, B., Jebb, S., Kopelman, P., McPherson, K., Thomas, S., Mardell, J., \& Parry, V. (2007) Foresight. Tackling obesities: Future choices - Project report. Accessed 12 ${ }^{\text {th }}$ April 2011 from http://www.bis.gov.uk/assets/bispartners/foresight/docs/obesity/17.pdf.

Carver, C.S., \& Scheier, M.F. (1982). Control theory: A useful conceptual framework for personality-social, clinical, and health psychology. Psychological Bulletin, 92, 111-135.

Chaudhury, M., \& Esliger, D. (2009) Accelerometry in adults. In R. Craig, J. Mindell, \& V. Hirani (eds). Health Survey for England 2008. Volume 1: Physical activity and fitness (pp59-88). Leeds: The NHS Information Centre.

Chen, G., Gully, S.M., \& Eden, D. (2001) Validation of a new general selfefficacy scale. Organizational Research Methods, 4, 62-83.

Chinn, D.J., White, M., Howel, D., Harland, J.O.E., \& Drinkwater, C.K. (2006) Factors associated with non-participation in a physical activity promotion trial. Public Health, 120, 309-319.

Cohen, J. (1992) A power primer. Psychological Bulletin, 112, 155-159. 
Craig, P., Dieppe, P., Macintyre, S., Michie, S., Nazareth, I., \& Petticrew, M. (2008) Developing and evaluating complex interventions. London: Medical Research Council.

Department for Communities and Local Government. (2011) The English Indices of Deprivation 2010. Accessed $17^{\text {th }}$ April 2011 from http://www.communities.gov.uk/documents/statistics/pdf/1871208.pdf.

Department of Health. (2004) Choosing health: Making healthier choices easier. London: Department of Health.

Department of Health. (2010) Health trainer national workforce audit 2009. Accessed $12^{\text {th }}$ October 2011 from http://www.londonhealthtrainers.nhs.uk/files/Health\%20Trainer\%20National\%20Wor kforce\%20Audit\%202008-09.pdf.

Dunlop, W.P., Cortina, J.M., Vaslow, J.B., \& Burke, M.J. (1996) Meta-analysis of experiments with matched groups or repeated measures designs. Psychological Methods, 1, 170-177.

Festinger L. (1957) A theory of cognitive dissonance. Stanford: Stanford University Press.

Gowers, A. (2010) NHS Health Trainers DCRS National HUB Report May 2010. Birmingham: Birmingham Primary Care Shared Services Agency.

Hardeman, W., Michie, S., Fanshawe, T., Prevost, A.T., McLoughlin, K., \& Kinmonth, A.L. (2008) Fidelity of delivery of a physical activity intervention: Predictors and consequences. Psychology \& Health, 23, 11-24.

Hirani, V., \& Stamatakis, E. (2006) Anthropometric measures, overweight and obesity. In: K. Sproston \& J. Mindell (eds). Health Survey for England 2004. Volume 
1, The health of minority ethnic groups (pp163-204). Leeds: The NHS Information Centre.

Kopelman, P. (2007) Health risks associated with overweight and obesity. Obesity Reviews, 8 (S1), 13-17.

Kotz, D., \& West, R. (2009) Explaining the social gradient in smoking cessation: it's not in the trying, but in the succeeding. Tobacco Control, 18, 43-46.

Lorig, K., Stewart, A., Ritter, P., Gonzalez, V., Laurent, D., \& Lynch, J. (1996) Outcome measures for health education and other health care interventions. Thousand Oaks: Sage Publications.

Michie, S., Abraham, C., Whittington, C., McAteer, J., \& Gupta, S. (2009) Effective techniques in healthy eating and physical activity interventions: a metaregression. Health Psychology, 28, 690-701.

Michie, S., Ashford, S., Sniehotta, F.F., Dombrowski, S.U., Bishop, A. \& French, D.P. (2011) A refined taxonomy of behaviour change techniques to help people change their physical activity and healthy eating behaviours - The CALO-RE taxonomy. Psychology and Health, 26, 1479-1498.

Michie, S., Jochelson, K., Markham, W.A., \& Bridle, C. (2009) Low-income groups and behaviour change interventions: a review of intervention content, effectiveness and theoretical frameworks. Journal of Epidemiology and Community Health, 63, 610-622.

Michie, S., Johnston, M., Abraham, C., Lawton, R., Parker, D., \& Walker A. (2005) Making psychological theory useful for implementing evidence based practice: a consensus approach. Quality \& Safety in Health Care, 14, 26-33.

Michie, S., Rumsey, N., Fussell, A., Hardeman, W., Johnston, M., Newman, S., \& Yardley, L. (2008) Improving health: changing behaviour - NHS health trainer 
handbook. Accessed 29 $9^{\text {th }}$ March 2011 from

http://www.dh.gov.uk/prod_consum_dh/groups/dh_digitalassets/@dh/@en/document s/digitalasset/dh_085778.pdf.

National Obesity Observatory. (2010) Adult obesity and socioeconomic status. Accessed 29 $9^{\text {th }}$ March 2011 from

http://www.noo.org.uk/uploads/doc/vid_7929_Adult\%20Socioeco\%20Data\%20Briefi ng\%20October\%202010.pdf.

Ogunbadejo, T., \& Nicholson, S. (2010) Adult fruit and vegetable consumption. In: R. Craig \& V. Hirani (eds). Health Survey for England 2009. Volume 1: Health and lifestyles (pp137-150). Leeds: The NHS Information Centre.

Paulhus, D.L. (1986) Self-deception and impression management in test responses. In A. Angleitner, \& J.S. Wiggins (eds). Personality assessment via questionnaire (pp142-165). New York: Springer.

Roth, M. (2009) Self-reported physical activity in adults. In R. Craig, J. Mindell \& V. Hirani (eds). Health Survey for England 2008. Volume 1: Physical activity and fitness (pp21-58). Leeds: The NHS Information Centre.

Schwarzer, R. (1992). Self-efficacy in the adoption and maintenance of health behaviors: Theoretical approaches and a new model. In R. Schwarzer (Ed.), Selfefficacy: Thought control of action (pp. 217-242). Washington, DC: Hemisphere.

Schwarzer, R. (2008). Modeling health behavior change: How to predict and modify the adoption and maintenance of health behaviors. Applied Psychology: An International Review, 57, 1-29.

Smith, D., Gardner, B., \& Michie, S. (2008) National Health Trainer end of year report 07/08. London: University College London. 
Smith, J., Gardner, B., \& Michie, S. (2009) Health Trainers national end of year report: 2008-09. London: University College London.

South, J., Woodward, J., \& Lowcock, D. (2007) New beginnings: stakeholder perspectives on the role of health trainers. Journal of the Royal Society for the Promotion of Health, 127, 224-230.

Tabassum, F. (2010) Adult anthropometric measures, overweight and obesity. In: R. Craig \& V. Hirani (eds) Health Survey for England 2009. Volume 1: Health and lifestyles (pp113-136). Leeds: The NHS Information Centre.

Tinsley, J., \& Jacobs, M. (2006) Deprivation and ethnicity in England: A regional perspective. Regional Trends, 39, 6.

Wilkinson, D.L., Jain, P., \& Hyland, L. (2007) National Health Trainer activity report. London: University College London.

Wilkinson, D., Sniehotta, F.F., \& Michie, S. (2011) Targeting those in need: baseline data from the first English NHS Health Trainer Service. Psychology, Health \& Medicine, 16, 736-748.

World Health Organisation (1998) Wellbeing measures in primary health care: The DepCare project. Copenhagen: WHO. 
Table 1. Client characteristics

\begin{tabular}{|c|c|c|c|c|c|c|}
\hline & \multicolumn{2}{|c|}{ All clients } & \multicolumn{2}{|c|}{$\begin{array}{l}\text { Clients with } \\
\text { healthy eating } \\
\text { goals }\end{array}$} & \multicolumn{2}{|c|}{$\begin{array}{c}\text { Clients with } \\
\text { physical } \\
\text { activity goals }\end{array}$} \\
\hline & $\mathbf{N}$ & $\%$ & $\mathbf{N}^{\circ}$ & $\%$ & $\mathbf{N}$ & $\%$ \\
\hline Age & 4418 & & 3346 & & 1072 & \\
\hline $18-25$ & 248 & 5.6 & 182 & 5.4 & 66 & 6.2 \\
\hline $26-35$ & 650 & 14.7 & 493 & 14.7 & 157 & 14.6 \\
\hline $36-45$ & 988 & 22.4 & 756 & 22.6 & 232 & 21.6 \\
\hline $46-55$ & 983 & 21.3 & 750 & 22.4 & 233 & 21.7 \\
\hline $56-65$ & 940 & 13.8 & 719 & 21.5 & 221 & 20.6 \\
\hline Over 65 & 609 & 13.8 & 446 & 13.3 & 163 & 15.2 \\
\hline Ethnicity & 4381 & & 3321 & & 1060 & \\
\hline White & (3647) & $(83.2)$ & (2890) & $(87.0)$ & $(757)$ & (71.4) \\
\hline White British & 3565 & 81.4 & 2838 & 85.5 & 727 & 68.6 \\
\hline White Irish & 28 & 0.6 & 18 & 0.5 & 10 & 0.9 \\
\hline Other White & 54 & 1.2 & 34 & 1.0 & 20 & 1.9 \\
\hline Asian & $(485)$ & (11.1) & (285) & (8.6) & $(200)$ & (18.9) \\
\hline Asian Indian & 135 & 3.1 & 89 & 2.7 & 46 & 4.3 \\
\hline Asian Pakistani & 273 & 6.2 & 157 & 4.7 & 116 & 10.9 \\
\hline Asian Bangladeshi & 64 & 1.5 & 30 & 0.9 & 34 & 3.2 \\
\hline Other Asian & 8 & 0.2 & 6 & 0.2 & 2 & 0.2 \\
\hline Black & $(175)$ & $(4.0)$ & (93) & $(2.8)$ & (82) & (7.7) \\
\hline Caribbean & 89 & 2.0 & 48 & 1.4 & 41 & 3.9 \\
\hline African & 77 & 1.8 & 38 & 1.1 & 39 & 3.7 \\
\hline Other Black & 9 & 0.2 & 7 & 0.2 & 2 & 0.2 \\
\hline Mixed $\dagger$ & (41) & $(0.9)$ & (31) & $(0.9)$ & (10) & $(0.9)$ \\
\hline $\begin{array}{c}\text { White and Black } \\
\text { Caribbean }\end{array}$ & 21 & 0.5 & 13 & 0.4 & 8 & 0.8 \\
\hline White and Black & 4 & 0.1 & 3 & 0.1 & 1 & 0.1 \\
\hline African & 4 & 0.1 & 4 & 0.1 & 0 & 0 \\
\hline $\begin{array}{l}\text { White and Asian } \\
\text { Any other mixed }\end{array}$ & 12 & 0.3 & 11 & 0.3 & 1 & 0.1 \\
\hline Other $\dagger$ & (33) & $(0.8)$ & (22) & $(0.7)$ & (11) & $(1.0)$ \\
\hline Chinese & 5 & 0.1 & 3 & 0.1 & 2 & 0.2 \\
\hline Other & 33 & 0.8 & 22 & 0.7 & 11 & 1.0 \\
\hline
\end{tabular}




\begin{tabular}{|ccccccc|}
\hline $\begin{array}{c}\text { HT-client ethnicity } \\
\text { similarity } \dagger^{\dagger}\end{array}$ & 4381 & & 3321 & & 1060 & \\
Matched & 2954 & 67.4 & 2381 & 71.7 & 573 & 54.1 \\
Unmatched & 1427 & 32.6 & 940 & 28.3 & 487 & 45.9 \\
\hline Deprivation & 4252 & & 3216 & & 1036 & \\
Q1 (most deprived) & 1836 & 43.2 & 1294 & 40.2 & 542 & 52.3 \\
Q2 & 1093 & 25.7 & 893 & 27.8 & 200 & 19.3 \\
Q3 & 688 & 16.2 & 555 & 17.3 & 133 & 12.8 \\
Q4 & 405 & 9.5 & 297 & 9.2 & 108 & 10.4 \\
Q5 (least deprived) & 230 & 5.4 & 177 & 5.5 & 53 & 5.1 \\
\hline
\end{tabular}

$\mathrm{N}$ varies across demographic variables due to missing data. Percentages represent the cell $\mathrm{N}$ expressed as a proportion of available data for each behaviour.

$\dagger$ Removed from subsequent analyses due to small $\mathrm{N}$.

$\dagger \dagger$ Clients and HTs were matched on census classification (e.g. Asian-Indian client \& Asian-Indian HT is deemed a 'match', Asian-Pakistani client \& Asian-Indian HT is deemed 'unmatched'). 
Table 2. Changes in BMI, behaviour and cognitions following use of the Health Trainer Service

\begin{tabular}{|c|c|c|c|c|c|}
\hline Outcome & $\mathbf{N}^{a}$ & $\begin{array}{l}\text { Baseline } \\
M(S D)\end{array}$ & $\begin{array}{c}\text { Post-HTS } \\
M(S D)\end{array}$ & $\begin{array}{c}\text { Mean } \\
\text { difference } \\
(95 \% C I)\end{array}$ & Cohen's $d^{b}$ \\
\hline \multicolumn{6}{|c|}{ Clients with healthy eating goals } \\
\hline BMI & 3164 & $\begin{array}{l}34.33 \\
(6.34)\end{array}$ & $\begin{array}{l}32.45 \\
(6.11)\end{array}$ & $\begin{array}{c}-1.88^{* *} \\
(-1.96,-1.80)\end{array}$ & .30 \\
\hline $\begin{array}{c}\text { Fruit and vegetables, daily } \\
\text { portions }\end{array}$ & 2376 & $\begin{array}{c}3.08 \\
(2.19)\end{array}$ & $\begin{array}{c}5.23 \\
(2.23)\end{array}$ & $\begin{array}{c}2.16^{* *} \\
(2.07,2.24)\end{array}$ & .97 \\
\hline Fried snacks consumed daily & 1869 & $\begin{array}{c}1.99 \\
(1.83)\end{array}$ & $\begin{array}{c}0.79 \\
(0.78)\end{array}$ & $\begin{array}{c}-1.19 * * \\
(-1.11,-1.27)\end{array}$ & .85 \\
\hline
\end{tabular}

\section{Clients with physical activity goals}

\begin{tabular}{cccccc} 
BMI & 595 & 32.46 & 31.24 & $-.1 .22^{* *}$ & .18 \\
& & $(6.86)$ & $(6.35)$ & $(-1.45,-0.98)$ & \\
Intensive activity sessions $^{c}$, & 637 & 0.63 & 1.71 & $1.08^{* *}$ & .46 \\
weekly & & $(2.06)$ & $(2.57)$ & $(0.87,1.24)$ & \\
Moderate activity sessions $^{c}$, & 921 & 3.06 & 4.77 & $1.71 * *$ & .42 \\
weekly & & $(4.37)$ & $(3.72)$ & $(1.43,1.99)$ & \\
\hline
\end{tabular}

\section{All clients}




\begin{tabular}{cccccc} 
BMI & 3759 & 34.03 & 32.26 & $-1.77 * *$ & .28 \\
& & $(6.46)$ & $(6.16)$ & $(1.69,1.85)$ & \\
General self-efficacy & 2385 & 21.69 & 23.90 & $2.21 * *$ & .47 \\
(range 0-32) & & $(4.91)$ & $(4.43)$ & $(1.98,2.43)$ & \\
Perceived general health & 2256 & 49.95 & 67.76 & $17.81 * *$ & .94 \\
(range 0-100) & & $(20.85)$ & $(17.13)$ & $(17.01,18.60)$ & .92 \\
Well-being & 855 & 11.71 & 16.03 & $4.33 * *$ & $(4.00,4.66)$ \\
(rage 0-25) & & $(4.94)$ & $(4.48)$ & & \\
\hline
\end{tabular}

** $\mathrm{p}<.001 .{ }^{\mathrm{a}} \mathrm{N}$ varies due to missing data. ${ }^{\mathrm{b}}$ Cohen's $d$ was manually calculated using means and standard deviations, in line with Dunlop,

Cortina, Vaslow, \& Bucke (1996). All $t$ values $>10.07$. ${ }^{\mathrm{c}}$ An activity 'session' is defined as a bout of 30 minutes or longer duration of moderate activity, or a bout of 20 minutes or longer duration of intensive activity. 
Table 3. Final regression models, predicting positive health behaviour change ${ }^{\mathrm{a}}$

\begin{tabular}{|c|c|c|c|c|c|c|c|}
\hline \multirow[b]{3}{*}{ Step \& predictor } & \multirow{2}{*}{$\begin{array}{c}\text { All clients } \\
\text { BMI reduction } \\
(N=3496)\end{array}$} & \multicolumn{3}{|c|}{ Clients with healthy eating goals } & \multicolumn{3}{|c|}{ Clients with physical activity goals } \\
\hline & & $\begin{array}{l}\text { BMI reduction } \\
\quad(N=2947)\end{array}$ & $\begin{array}{l}\text { Decreased fried } \\
\text { snack consumption } \\
\quad(N=1729)\end{array}$ & $\begin{array}{l}\text { Increased fruit } \\
\text { and vegetable } \\
\text { consumption } \\
(N=2203)\end{array}$ & $\begin{array}{l}\text { BMI reduction } \\
\quad(N=549)\end{array}$ & $\begin{array}{l}\text { Increased } \\
\text { moderate activity } \\
\quad(N=850)\end{array}$ & $\begin{array}{l}\text { Increased } \\
\text { intensive } \\
\text { activity } \\
(N=594)\end{array}$ \\
\hline & $\beta$ & $\beta$ & $\beta$ & $\beta$ & $\beta$ & $\beta$ & $\beta$ \\
\hline $\begin{array}{l}\text { Step 1 } \\
\text { Baseline score on outcome } \\
\text { variable }\end{array}$ & $.30 * *$ & $.27 * *$ & $.91 * *$ & $-.46^{* *}$ & $.38 * *$ & $-.64 * *$ & $-.45 * *$ \\
\hline$\frac{\text { Step } 2}{\text { Duration of HTS }}$ & $.08^{* *}$ & $.11 * *$ & .00 & & & & \\
\hline No. of reviews & .00 & -.01 & .01 & & & & \\
\hline$\frac{\text { Step } 3}{\text { Duration } x \text { no of reviews }}$ & $-.05 *$ & $-.06^{*}$ & .00 & & & & \\
\hline $\begin{array}{l}\text { Step } 4 \\
\text { Client ethnicity } \\
\text { Asian vs (White \& Black) }\end{array}$ & $-.06 * *$ & $-.07 * *$ & -.02 & & & & \\
\hline Black vs (Asian \& White) & -.02 & -.01 & .00 & & & & \\
\hline Client deprivation & .04 & .04 & .00 & & & & \\
\hline HT-client ethnicity match & .03 & .03 & .02 & & & & \\
\hline $\begin{array}{l}R^{2} \\
\text { Model F }\end{array}$ & $\begin{array}{c}.11 \\
53.92 * *\end{array}$ & $\begin{array}{c}.10 \\
40.81 * *\end{array}$ & $\begin{array}{c}.82 \\
1003.51^{* *}\end{array}$ & $\begin{array}{c}.21 \\
597.35^{* *}\end{array}$ & $\begin{array}{c}.15 \\
93.23^{* * *}\end{array}$ & $\begin{array}{c}.40 \\
574.66^{* *}\end{array}$ & $\begin{array}{c}.21 \\
152.72 * * *\end{array}$ \\
\hline
\end{tabular}

$* * * p \leq .001, * * p \leq .01, * p \leq .05$. ${ }^{a}$ Outcome variables have been coded so that higher scores indicate greater positive behaviour change (increased $\mathrm{F} \& \mathrm{~V}$ consumption, decreased fried snack consumption, reduced BMI, increased activity sessions). Ethnicity dummy variables coded as $1=$ Asian, $0=$ White $\&$ Black (Asian vs White \& Black) and $1=$

Black, $0=$ Asian \& White. Deprivation dichotomised and coded as $1=$ most deprived, $2=$ least deprived. Betas derived from the final hierarchical regression model. Matched HT-client ethnicity similarity coded as $1=$ not matched, $2=$ matched. 
Figure. Data collection sequence

\begin{tabular}{|c|c|c|c|}
\hline Measures & & & Measures \\
\hline BMI (height, weight) & & & BMI (height, weight) \\
\hline Behaviour & & & Behaviour \\
\hline Self-efficacy & & & Self-efficacy \\
\hline Perceived health & & & Perceived health \\
\hline Wellbeing & & & Wellbeing \\
\hline Baseline assessment & Health goals set & Progress review(s) & Follow-up \\
\hline
\end{tabular}

